\title{
Hasankeyf İnsanlarının Paleodemografik Analizi
}

\section{Ayşe ACAR}

Öz

Arkeolojik toplumlar üzerinden yapılan paleodemografik çalışmalarla, toplumların nüfus yapısı ve büyüklüğü hakkında bilgi sahibi olunabilir. Çalışmanın amacı, llısu Baraj Projesi kapsamında Hasankeyf ilçesinde ortaya çıkarılan insan iskelet kalıntılarını paleodemografik açıdan değerlendirmektir. Çalışmanın materyalini; Batman ili, Hasankeyf ilçesi, Ilısu Baraj Projesi kapsamında, Er Rızk Camii alanında bulunan P237 no.lu parselde güneyden kuzeye A1 ve B1 plan karelerdeki arkeolojik kazı çalışmasında elde edilen insan kemikleri oluşturmaktadır. Çalışmada 63 adet basit toprak mezar bulunmuş, birey sayısı 82 kişi olarak tahmin edilmiştir. Veri analizi sonucunda; bireylerin \%23,17’i erkek, \%8,5’i kadın, \%34'ü bebek ve çocuk olarak tahmin edilirken, \%34 oranında cinsiyet tahmin edilememiştir. Yaşam süreleri bütün bireyler için 17,53 yıldır. Yetişkin bireylerin ortalama yaşam uzunlukları kadın bireylerde 35,25 yıl, erkek bireylerde 35,66 yıldır. Hasankeyf toplumunda en yoğun ölümler 1-5 yaş arasındaki bireylerde \%13,41 oranındadır. Patolojilerin değerlendirilmesi ile toplumun beslenme alışkanlıklarının hayvansal ürünlere yönelik olduğu söylenebilir. Boy uzunluğu tibia uzunluğuna göre ortalama $171,38 \pm 4,00 \mathrm{~cm}$ olarak hesaplanmıştır. Sonuç olarak, Hasankeyf toplumu bireylerinin paleodemografik analizi ile Güneydoğu Anadolu Bölgesi için arkeolojik veri kaynağı niteliği taşımaktadır.

Anahtar Kelimler: Paleodemografi, Osteoloji, Orta Çağ, Hasankeyf.

\section{Paleodemographic Analysis of Hasankeyf People}

\begin{abstract}
Information about the population structure and the size of the societies can be obtained through paleodemographic studies on archaeological societies. The aim of the study is to evaluate the human skeleton remains from Hasankeyf excavation of Batman, uncovered as part of the Ilısu Dam Project, from a paleodemographic perspective. The human bones have
\end{abstract}

1 Dr. Öğr. Üyesi, Mardin Artuklu Üniversitesi, Edebiyat Fakültesi Antropoloji Bölümü, ayseacar@artuklu.edu.tr, ORCID ID: 0000-0002-1327-6378. 
been examined in this study were obtained from the $A 1$ and $B 1$ plan squares in the Trench P237 within the area of Er Rızk Mosque, Hasankeyf. A total of 82 individuals have been estimated from the remains of 63 simple ground graves. Among them, $23.17 \%$ have been identified as male, $8.5 \%$ as female, $34 \%$ as infant and child, and $34 \%$ as undetermined sex. Life expectancy has been observed as 17.53 years for all individuals, whereas the average life span of adults is estimated to be 35.25 years for females and 35.66 years for males, respectively. The most frequent death rates in the Hasankeyf community have been observed amongst individuals aged between one and five, at a fatality rate of $13.41 \%$. The pathologies show that the nutritional habits of the society were mainly associated with animal-based food. The average body height was calculated as $171.38 \pm$ $4.00 \mathrm{~cm}$ according to the length of the tibia. Overall, the paleodemographic data of the individuals from Hasankeyf present very significant archaeological information about the medieval people groups in Southeastern Anatolia.

Keywords: Paleodemography, Osteology, Medieval period, Hasankeyf

\section{Extended Abstract}

The aim of the study is to evaluate the human skeleton remains from Hasankeyf excavation of Batman, uncovered as part of the Ilisu Dam Project, from a paleodemographic perspective. The human bones have been examined in this study were obtained from the $A 1$ and $B 1$ plan squares in the Trench P237 within the area of Er Rizk Mosque, Hasankeyf. A total of 82 individuals have been estimated from the remains of 63 simple ground graves. $23.17 \%$ of these individuals have been identified as male, $8.5 \%$ as female, $34 \%$ as infant and child, and $34 \%$ as undetermined sex. One of the best indicators of the health status of societies is the life expectancy of individuals. It has been observed that $34.14 \%$ of Hasankeyf people died before their age of 18 , whereas the average life expectancy for all individuals has been observed to be 17.53 years. However, the average life expectancy of the adult female individuals has been estimated as 35.25 years, while it has been estimated 35.66 years for male individuals. Among the age groups, the young middle adult group comprised of the highest number of female individuals. Surprisingly, the very similar rate has been observed while comparing with the infant and child mortality rates, suggesting that most of the female individuals in this age group could have been died of giving birth. On the other hand, the most frequent deaths among Hasankeyf people groups have been observed in the age group between one and five, with a mortality rate of $13.41 \%$. Looking at the graph of the survival chance (Ix), the lowest acceleration has been observed between the ages 20 and 30, with a rapid acceleration between the ages from 0 and 5 . In the death probability (qx), low slope has been observed in the individuals of young population group, while it intensified with the increase in age. The average life expectancy rate (ex) has been observed about 25 years old. The most significant decrease was between the ages of 40 to 45 and 45 to 50 years. Long bones (femur, tibia, 
humerus) have been preferred for the estimation of body height, which is one of the indicators reflecting the physical structures and health conditions of people. Although the complete long bones were comparatively low in number, in order to have an overall idea about the body height of the people group, the metric measurement of adult individuals was calculated using the height-length formula developed by Trotter and Gleser. According to the femur length, the average height of 4 individuals has been calculated to be $163.54 \pm 3.94 \mathrm{~cm}$, while the average body height was calculated as $171.38 \pm 4.00 \mathrm{~cm}$ according to the length of the tibia. Caries, abscesses, pre-mortem loss and calculus have been examined for understanding the dental and jaw pathologies. The rate of caries has been observed $2.56 \%$, abscess $2.38 \%$, antemortem tooth loss $29.25 \%$, and calculus has been observed as $5.76 \%$. When the pathologies are evaluated in terms of sex, a higher rate of caries, antemortem tooth loss and calculus has been observed in male individuals while a higher rate of abscess has been found in female individuals. Among the age groups, overall higher rate of caries has been observed in middle adult group, whereas antemortem tooth loss has been observed more in old age group. Overall, the pathologies indicate that the nutritional habits of the medieval society of Hasankeyf were mostly associated with meat and animal-based food products. Since paleodemographic analysis of human skeletal remains from archaeological context greatly contributes our better understanding about the health, nutrition, food habit, as well as significant socio-economic status of the past societies, the result of this study no only reveled the biological and socio-cultural status of the people groups of Hasankeyf, it could also be an important sources to understand the status of medieval people groups in Southeastern Anatolia in general. 


\section{Giriş}

Batman ili, Hasankeyf ilçesi sınırları içerisinde bulunan kazı alanı, yol genişletme çalışması esnasında bulunan bir medrese avlusudur (Fotoğraf 1). Medresenin adı arşiv taramalarından bulunmaya çalışılmaktadır. Medresenin avlusunda yapılan kazı çalışmaları esnasında avlu içinde kanal, havuz olarak kullanılan alanda temizlik çalışmaları esnasında, bu alanların içinin medreseden sonraki dönemde mezar olarak kullanıldığı tespit edilmiştir. Basit toprak mezar özelliğinde 63 adet mezar tespit edilmiştir. Gömü tipleri Müslüman gömü geleneğine göre defnedilmiştir. Mezar etrafında çeşitli hayvanlara ait (büyükbaş, küçükbaş, köpek, at. vb.) iskelet kalıntıları da tespit edilmiştir.

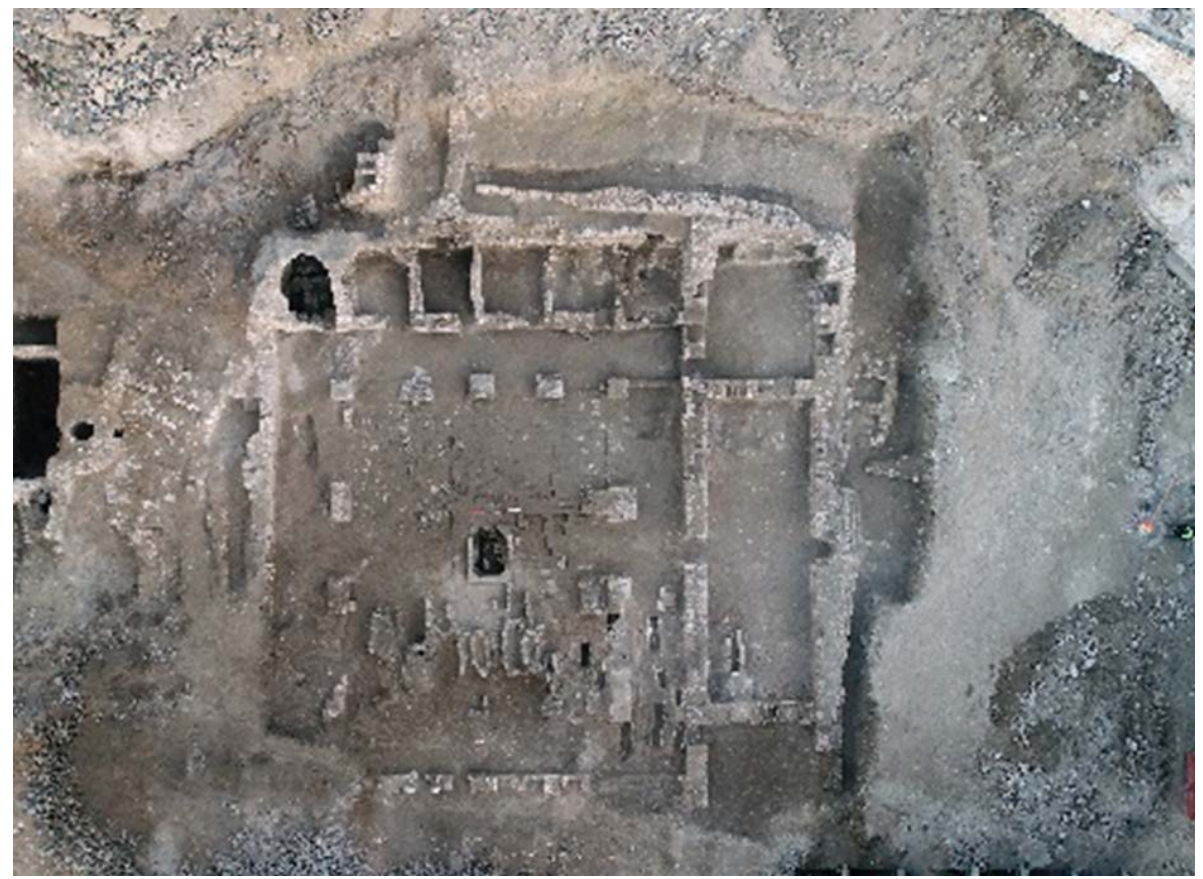

\section{Fotoğraf 1: Er Rızk Camii alanında bulunan P237 no.lu parsel}

Arkeolojik toplumlar üzerinden yapılan paleodemografik analizlerle, toplumun nüfus yapısı ve büyüklüğü hakkında bilgi sahibi olunabilir (Angel, 1969; Meindl ve Russell, 1998). Birey sayısı, cinsiyet ve yaş tahminleri yapılan toplumun istatistiksel hesaplamalarla yaşam tabloları oluşturulur. Oluşturulan yaşam tabloları ile nüfus büyüklüğü, ölüm ve doğurganlık oranları, yaş gruplarına göre dağılımları, büyüme hızı ve yaşam beklentisi belirlenebilir.

Yaşam tablosunun oluşması için birey sayısı tahmini önemli bir aşamadır. Birey sayısı genellikle tek olan kemiklerden yapılabildiği gibi çift olan kemiklerin de yönlerinin tahmini ile yapılabilir. Bu şekilde en az veya en çok şeklinde birey sayısı tahmini yapılabilir (Buikstra ve Ubelaker, 1994). 
Cinsiyet tahmini ikinci basamağı oluşturmaktadır. Cinsiyet tahmini morfolojik (Krogman ve İşcan 1986: 208; İşcan ve Miller-Shaivitz, 1984; Bass, 1995) yapılabildiği gibi metrik (Krogman ve İşcan 1986; Çöloğlu ve İşcan, 1998) metotlar kullanılarak da yapılabilir. Kemikler üzerinde cinsiyetin en iyi yapıldığı kemik coxae kemiğidir (WEA, 1980). Coxae kemiğinin bulunmadığı veya deforme olduğu durumlarda kullanılan bölümler kafatası, uzun kemikler olarak sıralanabilir.

Yaş tahmini ile toplumların yaşam uzunlukları tahmin edilebilir. Farklı yaş gruplarına uygun olarak kullanılan kriterler uygulanmıştır. Bebek ve çocuklar için en çok kullanılan dişlerin çıkma dönemleri iken yetişkinler için epifizlerin kapanma dönemi, suturların kapanma durumu, dental aşınma derecesi ile yaş tahmini yapılabilir (WEA, 1980; Scheuer ve Black, 2000; Brothwell, 1981; Perizonius, 1984; Lovejoy, 1985). Yaşam uzunluklarının tahmini ile toplumların sağlık yapıları hakkında fikir sahibi olunabilir (Erdal, 2011). Geçmişten günümüze baktığımızda yaşam uzunluğunun gittikçe artan bir değerde olduğu söylenebilir (Güleç vd., 2009).

İnsanların fiziksel yapılarını ve sağlık durumlarını yansıtan göstergelerden biri de boy uzunluğudur (Scheuer ve Black, 2000). Boy uzunluğunu etkileyen etmenler arasında genetik, çevresel (coğrafya, iklim vb.) ve sosyo-ekonomik faktörler sayılabilir. Hasankeyf bireylerinin iskeletlerinin korunma durumunun zayıf olması sebebiyle, boy tahmini için gerekli olan uzun kemiklerin metrik incelemesi sınırlı sayıdaki kemik üzerinden yapılmıştır.

Bu çalışmanın amacı; Hasankeyf, Er Rızk Camii alanında bulunan P237 no'lu parselde yapılan arkeolojik kazı çalışması sonucunda elde edilen insan iskelet kalıntılarını Anadolu'da yaşamış aynı dönem ve yakın dönem toplumlarla karşılaştırarak toplumun demografik yapısını, boy uzunluğu, diş, çene ve vücut patolojilerini tespit ederek toplumsal yapıyı değerlendirmektir. Hasankeyf üzerinde yapılan bilimsel çalışmalara, bölgedeki insanların genel sağlık durumu ve toplumsal yapının belirlenmesi ile katkı sunması amaçlanmıştır.

\section{Materyal Metot}

Çalışmanın materyalini Batman ili, Hasankeyf îcçesi, Ilısu kurtarma kazısı kapsamında 2019 yılı içinde başlayıp aynı yıl tamamlanan iskelet materyallerden oluşmaktadır. İskelet materyaller incelenmek üzere, Batman Müzesi Müdürü Şehmus Genç izni ile 13. 12. 2019 tarihinde paleodemografik analizler için Mardin Artuklu Üniversitesi Antropoloji Bölümü, Osteoloji laboratuvarına getirilmiștir.

Hasankeyf, Er Rızk Camii alanında bulunan P237 no'lu parselde ortaya çıkarılan medrese avlusunda 63 adet basit toprak mezar özelliğindeki iskelet kalıntılardan çoklu gömü olması nedeniyle 82 kişi tahmin edilmiştir. İskelet materyallerin korunma durumu zayıftır. 
Laboratuvara gelen kemikler için öncelikle temizlik ve onarım çalışması yapılmıştır. Birey sayısı vücuttaki tek kemiklerden veya çift olan kemiklerin yönü tahmin edilerek yapılmıştır. Cinsiyet için morfolojik kriterler kullanılmıştır. Önce coxae kemiği, sonra maxilla ve mandibula kemiği, uzun kemikler kullanılarak bireylerin cinsiyeti tahmin edilmiştir (WEA, 1980; Krogman ve İşcan, 1986; Bass, 1995). Yaşlandırma; bebek ve çocuk bireylerde, dişlerin sürme dönemlerine göre geliştirilen dental yaşlandırma (Buikstra ve Ubelaker, 1994; Brothwell, 1981), genç erişkinlerde daimi köklerin kapanması (Ubelaker, 1991), erişkin bireylerde dental aşınma (Olivier, 1969; Demirjian vd., 1973;Brothwell, 1981) metotları kullanılmıştır. Bebek ve çocuk bireylerde yaş aralıkları, 38-40 hafta yeni doğan, 1-12 ay bebek, 15 yaş çocuk, 6-11 yaş orta çocukluk, 12-17 yaş adölesan olarak belirlenmiştir. Yetişkin bireylerde, 18-25 yaş genç erişkin, 26-35 yaş genç orta erişkin, 36-45 yaş orta yetişkin, +46 yaş ve üstü ileri erişkin olarak değerlendirilmiştir. Diş ve çene patolojileri makroskobik olarak incelenmiştir. Paleopatolojik değerlendirmeler için Brothwell'in (1981), Ortner ve Putschar'ın (1981), Hilson'un (1990), Buikstra ve Ubelaker'ın (1994) ve Aufderheide ve Rodriguez-Martin'in (1998) çalışmalarından faydalanılmıştır.

Boy tahmini için Trotter ve Gleser'in geliştirdiği formül kullanılmıştır (Trotter ve Gleser, 1951). Yaşam tablosu için kullanılan formüller Üner (1972)'e göre belirtilen formüller kullanılmıştır. İstatistik analizleri Microsoft Office 2007 Excel programı kullanılmıştır. aralıklarını,

$\mathrm{X}=$ Yaşam tablosu oluşturulurken değerlendirmeye giren bireylerin yaş

$\mathrm{Dx}=\mathrm{X}$ yaşındaki ölümleri,

$\mathrm{I}=\mathrm{X}$ yaşında hayatta kalanların sayısını,

$\mathrm{dx}=\mathrm{X}$ yaşındaki ölümlerin yüzdesini,

$\mathrm{dx}=\mathrm{qx} . \mathrm{Ix} \mathrm{dx}=(\mathrm{Dx} /$ toplam nüfus $) \mathrm{x} 100$,

Ix= dx / qx, qx=X yaşında ölüm olasılığı (ölümlülük olasıllğı),

$\mathrm{qx}=\mathrm{dx} / \mathrm{lx}$ toplam

Lx (yaşanan yılların sayısı): yaş aralığında bütün bireylerin yaşadığı yılların

sayısıdır.

$L x=5 x(\mid x+l o) / 2$ lo:bir sonraki yaş aralığında yaşayanların sayısı

${ }^{\circ} e_{x}$ (yaşam beklentisi): yaş aralığında ölen bireylerin ölmemeleri halinde ne kadar daha yaşayacaklarını ifade eder.

${ }^{\circ} e_{x}=T x / l x$ formülü uygulanmıştır. (Üner, 1972). 


\section{Bulgular}

Hasankeyf toplumunun birey sayısı, 63 adet mezardan çıkan kalıntıların değerlendirilmesi sonucunda 82 kişi olarak tahmin edilmiştir. Tablo 1'de bireylerin yaş gruplarına göre dağılımı gösterilmiştir. Bir toplumun sağlık durumunun en iyi göstergelerinden biri bebek ve çocuk bireylerin ölüm oranlarıdır. Tablo 1'e göre toplumdaki yoğunluk bebek ve çocuk grubunda görülmektedir. Toplumun \%34,14'ü 18 yaşına gelemeden hayatını kaybetmiştir. Yetişkin olmayan bireylerde yoğunluk 1-5 yaş arasındaki çocuk bireylerde \% 13,41 oranında hesaplanmıştır. Hasankeyf bireylerinde yaşları tahmin edilebilen 27 bireyin ortalama yaşam uzunlukları 5,78 yıl olarak tahmin edilmiștir.

Yetişkin grupta yaşları tahmin edilemeyen bireylerin oranı, korunma durumunun zayıf olması sebebiyle \% 42,68 ile yüksek bir değerdedir. Yaşları tahmin edilebilen yetişkin bireylerde yoğunluk genç orta yetişkin yaş grubunda (\% 13,41) tahmin edilmiştir.

Tablo 1: Hasankeyf bireylerinin yaş grupların göre dağılımı (N: birey sayısı)

\begin{tabular}{|l|l|l|}
\hline Yaş Grubu & N & \multicolumn{1}{|c|}{$\%$} \\
\hline Yenidoğan (38-40 Haftalık) & 1 & 1,21 \\
\hline Bebek (1-12 ay) & 7 & 8,53 \\
\hline Çocuk (1-5 yaş) & 11 & 13,41 \\
\hline Orta Çocukluk (6-11 yaş) & 4 & 4,87 \\
\hline Adölesan (12-17 yaş) & 5 & 6,09 \\
\hline Genç Yetişkin (18-25 yaş) & 1 & 1,21 \\
\hline Genç Orta Yetişkin (26-35 yaş) & 11 & 13,41 \\
\hline
\end{tabular}




\begin{tabular}{|l|l|l|}
\hline Orta Yetişkin (36-45 yaș) & 3 & 3,65 \\
\hline İleri Yaş +46 yaş & 4 & 4,87 \\
\hline Yaş Bilinmeyen & 35 & 42,68 \\
\hline Toplam & 82 & 100 \\
\hline
\end{tabular}

Hasankeyf toplumunda mezardaki iskelet kalıntıların çoğunluğu bütünlük taşımamaktadır. Bu durum cinsiyet tahmini çalışmalarını zorlaştırmaktadır. Cinsiyeti tahmin edilebilen bireylerin yaş ve cinsiyet dağılımı Tablo 2'de gösterilmiştir. Tablo 2'ye göre, kadın bireylerin sayısı 7, erkek bireylerin sayısı 19, cinsiyeti tahmin edilemeyen birey sayısı 28 olarak tahmin edilmiştir. Toplumda yaşları tahmin edilemeyen birey sayısı 35 kişi ile \% 64,81'lik bir oranı oluşturmaktadır. Hasankeyf toplumunda kadın bireyler oldukça az sayıda temsil edilmektedir. Kadın bireylerin en yoğun olduğu yaş grubu, genç orta yetişkin grubunda görülmektedir. Bu dönem bebek ve çocuk ölüm oranları ile karşılaştırılarak düşünüldüğünde kadınların doğurganlık döneminin en yoğun olduğu yaş dönemi ile paralellik taşıdığı görülmüştür. Erkek bireylerin yoğun olduğu yaş grubu, kadınlarda olduğu gibi genç orta yetişkin grubunda görülmüştür.

Tablo 2: Yaş grupları ve Cinsiyet dağılımı

\begin{tabular}{|c|c|c|c|c|c|c|c|c|}
\hline Yaş Grubu & Kadın & $\%$ & Erkek & $\%$ & Cinsiyet B. & $\%$ & Toplam & $\%$ \\
\hline $\begin{array}{l}\text { Genç } \\
\text { Yetişkin (18- } \\
25 \text { yaş) }\end{array}$ & 0 & 0 & 0 & 0 & 1 & 1,85 & 1 & 1,85 \\
\hline $\begin{array}{l}\text { Genç Orta } \\
\text { Yetişkin (26- } \\
35 \text { yaş) }\end{array}$ & 3 & 5,5 & 6 & 11,11 & 2 & 3,7 & 11 & 20,37 \\
\hline
\end{tabular}




\begin{tabular}{|c|c|c|c|c|c|c|c|c|}
\hline $\begin{array}{l}\text { Orta } \\
\text { Yetişkin (36- } \\
45 \text { yaş) }\end{array}$ & 0 & 0 & 3 & 5,5 & 0 & 0 & 3 & 5,55 \\
\hline $\begin{array}{l}\text { İleri Yaş +46 } \\
\text { yaş }\end{array}$ & 1 & 1,85 & 3 & 5,5 & 0 & 0 & 4 & 7,4 \\
\hline $\begin{array}{l}\text { Yaş } \\
\text { Bilinmeyen }\end{array}$ & 3 & 5,5 & 7 & 12,96 & 25 & 46,29 & 35 & 64,81 \\
\hline Toplam & 7 & 12,96 & 19 & 35,18 & 28 & 51,85 & 54 & 100 \\
\hline $\begin{array}{l}\text { Genel } \\
\text { Toplam }\end{array}$ & & & & & 54 & 100 & & \\
\hline
\end{tabular}

Toplumların sağlık durumlarının en iyi göstergelerinden biri de bireylerin yaşam uzunluklarının tahmin edilmesidir. Hasankeyf toplumunda yaşları belirlenebilen tüm bireylerin yaşam uzunluğu 17,53 yıl olarak hesaplanmıştır. Yetişkin bireylerin ortalama yaşam uzunlukları kadın bireylerde 35,25 yıl, erkek bireylerde 35,66 yıldır. Kadın ve erkek bireylerin ortalama yaşam süreleri 35,55 yıl olarak tespit edilmiştir.

\subsection{Demografik Yapı}

Tablo 3'te beşer yıl ara ile oluşturulmuş yaşam tablosu bulunmaktadır. Yaşları tahmin edilebilen birey değerlendirilmeye alınmıştır. Toplumdaki birey sayısı 82 iken yaşları tahmin edilebilen birey sayısı 46'dır. 
Tablo 3: Hasankeyf bireylerinin beșer yıl aralı yaş grubu yaşam tablosu

(X: Yaş aralıkları, Dx: $X$ yaşındaki ölümleri, $\mathrm{dx}=\mathrm{X}$ yaşındaki ölümlerin yüzdesini, Ix: $X$ yaşında hayatta kalanların sayısını, qX=X yaşında ölüm olasılığı (ölümlülük olasılı̆̆ı), Lx: yaşanan yılların sayısı, Tx: Yaşanan yılların toplamı, ${ }^{\circ}{ }_{*}$ : yaşam beklentisi)

\begin{tabular}{|c|c|c|c|c|c|c|c|}
\hline$X$ & Dx & $d x$ & Ix & $q x$ & $L x$ & Tx & ex \\
\hline $0-4,9$ & 14 & 30,43 & 100 & 0,3 & 423,91 & 1792,43 & 17,92 \\
\hline $5-9,9$ & 7 & 15,21 & 69,56 & 0,21 & 309,78 & 1368,52 & 19,67 \\
\hline $10-14,9$ & 3 & 6,52 & 54,34 & 0,12 & 255,43 & 1058,74 & 19,48 \\
\hline $15-19,9$ & 3 & 6,52 & 47,82 & 0,13 & 222,82 & 803,31 & 16,79 \\
\hline $20-24,9$ & 1 & 2,17 & 41,3 & 0,05 & 201,08 & 580,49 & 14,05 \\
\hline $25-29,9$ & 6 & 13,04 & 39,13 & 0,33 & 163,04 & 379,41 & 9,69 \\
\hline $30-34,9$ & 6 & 13,04 & 26,08 & 0,5 & 97,82 & 216,37 & 8,29 \\
\hline $35-39,9$ & 2 & 4,34 & 13,04 & 0,33 & 54,34 & 118,55 & 9,09 \\
\hline $40-44,9$ & 0 & 0 & 8,69 & 0 & 43,47 & 65,21 & 7,5 \\
\hline $45-49,9$ & 4 & 8,69 & 8,69 & 1 & 21,73 & 21,73 & 2,5 \\
\hline
\end{tabular}

Tablo 3'te yaş gruplarındaki birey sayısına bakıldığında en fazla birey 0-5 yaş arasında (N:14) tahmin edilmiştir. Birey bulunmayan yaş aralığı 40-44,9 yaş arasındadır. Hasankeyf bireylerinin ölüm oranı $(\mathrm{dx})$ grafiğine bakıldığında en 
yüksek oranın bebek ve çocuklarda olduğu görülmektedir (Grafik 1). 25-29,99 ve 30-34,99 yaş arasındaki bireylerde eşit oranda ölüm oranı hesaplanmıştır.

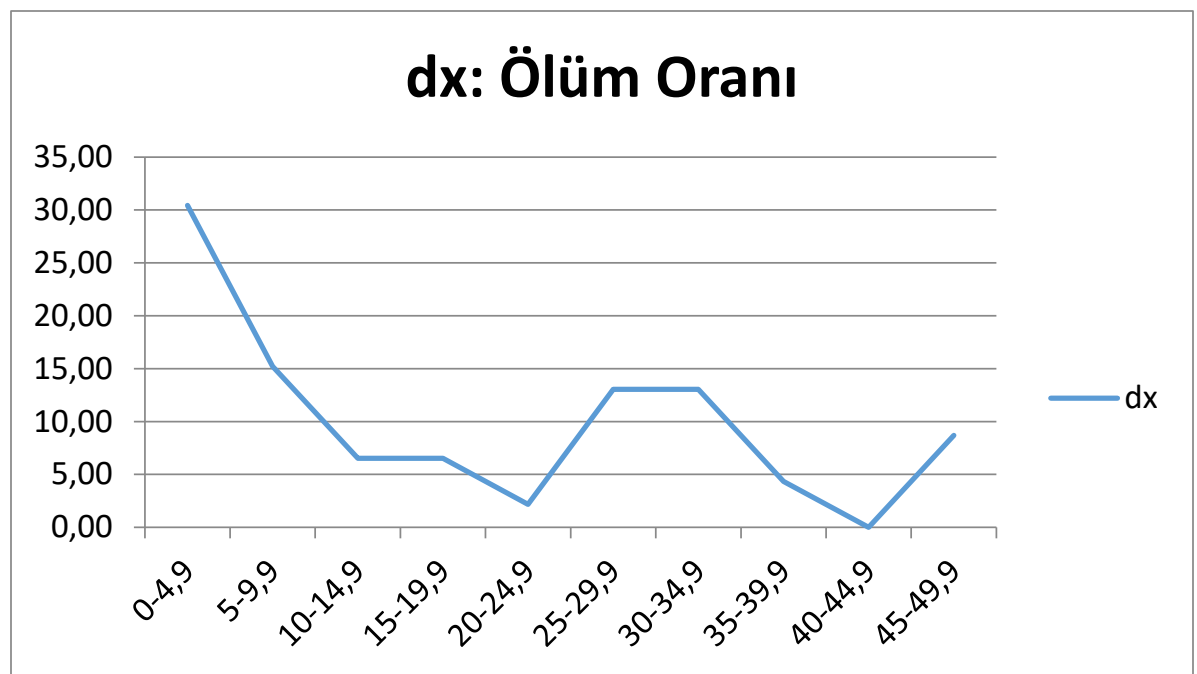

\section{Grafik 1: Hasankeyf bireylerinin yaş gruplarına göre ölüm oranı}

Hasankeyf bireylerinin hayatta kalma şansı (Ix) grafiğine bakıldığında 0-5 yaş arasında eğim hızı bir ivmeyle seyrederken, 20-30 yaş arasında eğim en düşük ivmede seyretmektedir (Grafik 2). Diğer yaş aralıklarında azalan bir ivmeyle düşüş devam etmektedir.

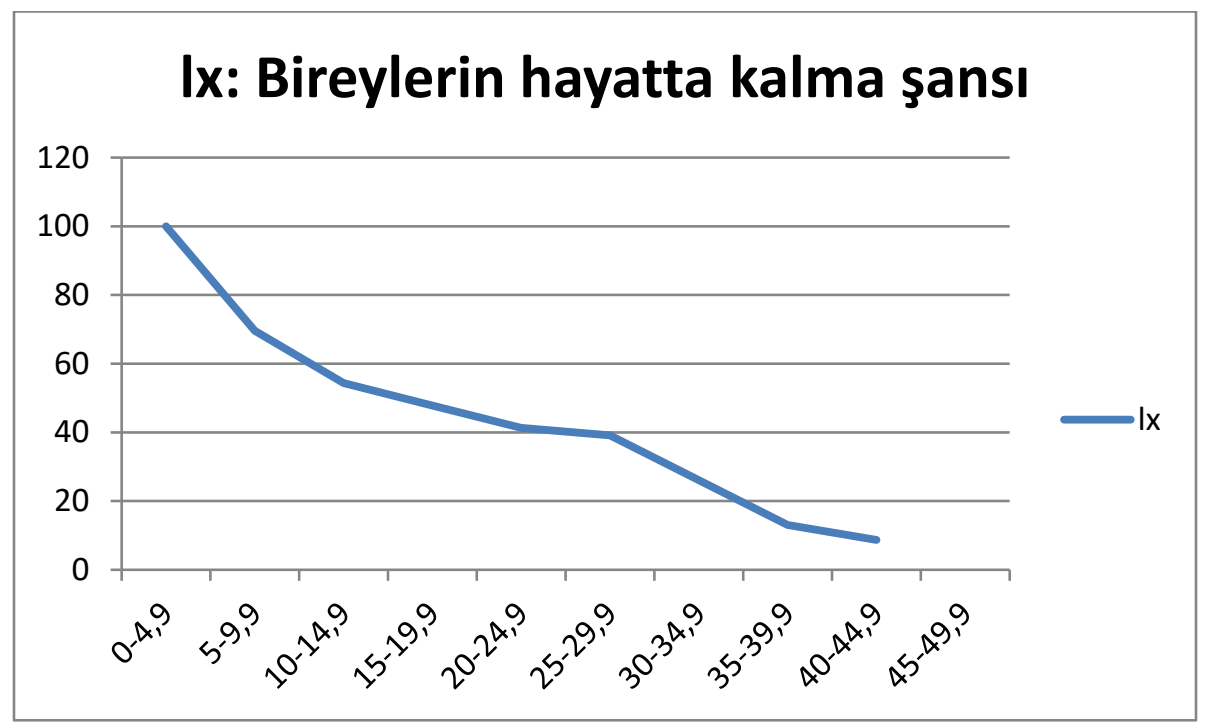

Grafik 2: Hasankeyf bireylerinin hayatta kalma şansı 
Ölüm olasılığı (qx), toplumdaki genç nüfusu oluşturan bireylerde düşük eğim biçiminde iken, yaş ilerledikçe eğim artmaktadır (Grafik 3). 20-25 yaş arasındaki bireylerde en düşük değer hesaplanmıştır.

\section{qx:Ölüm olasığı}

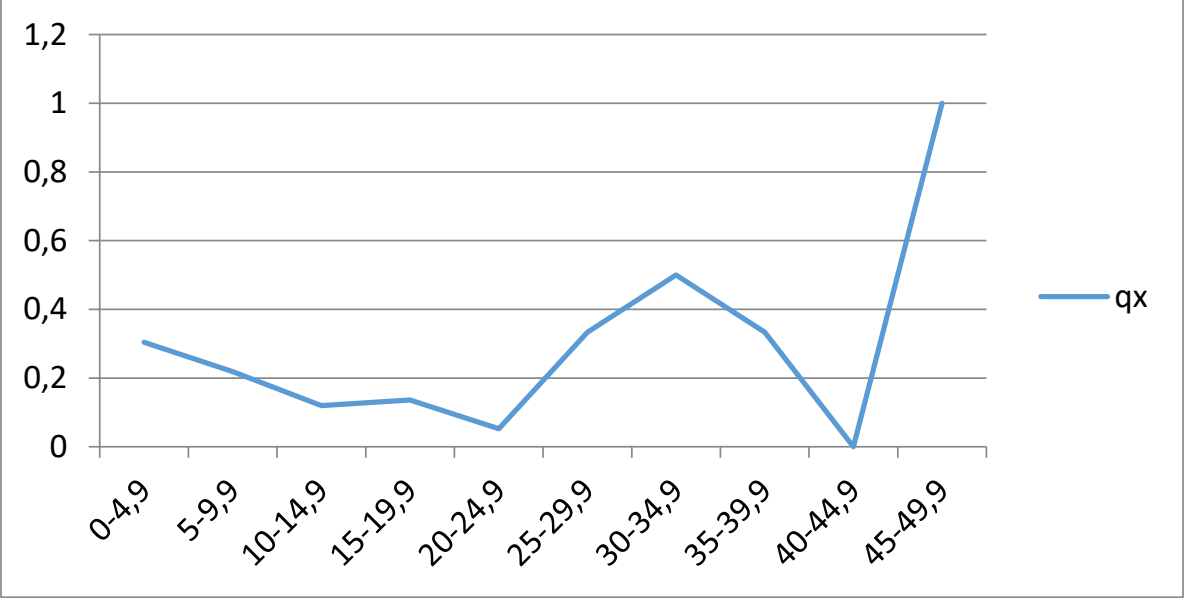

\section{Grafik 3: Hasankeyf bireylerinin ölüm olasılığı}

Yaşam beklentisi oranı (ex), Grafik 4’te görüldüğü gibi 25 yaşa kadar hemen hemen aynı değerdedir. En belirgin düşüş 40-45 ve 45-50 arasında olmuştur. 20-25 yaş ile 25-30 yaş arasında düşme görülürken 30-35 arasında diğer yıllara göre değişiklik göstererek yaşam beklentisi oranında artış gözlenmiştir.

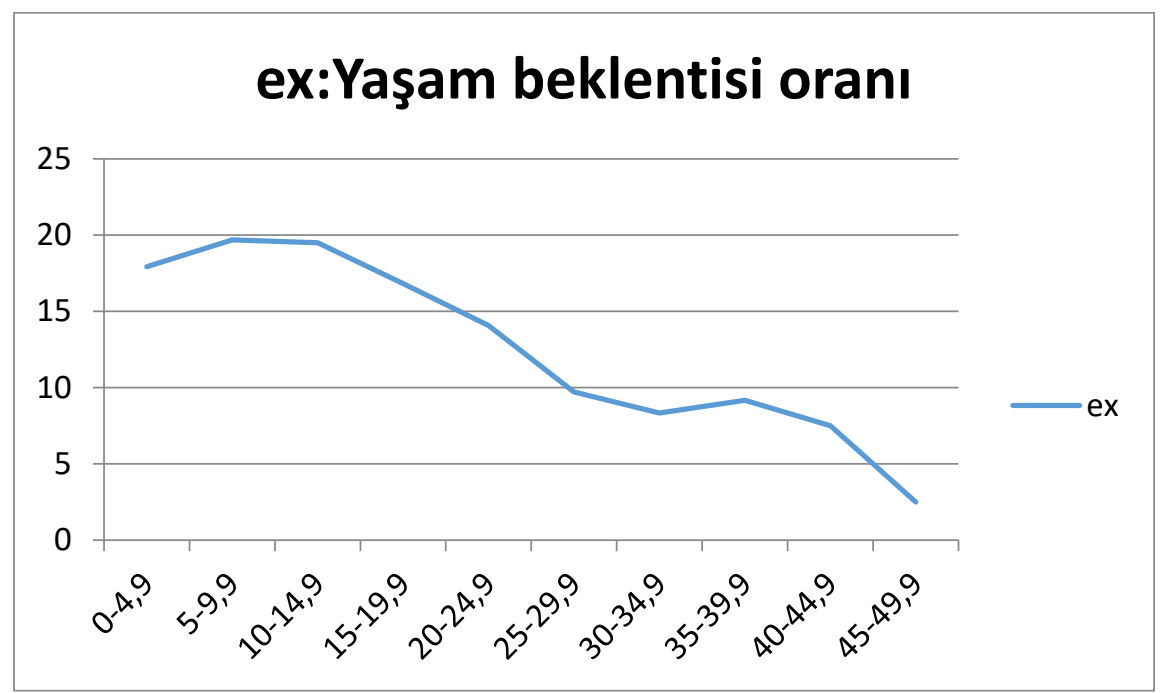

Grafik 4: Hasankeyf bireylerinin yașam beklentisi oranı 
Hasankeyf bireyleri arasında kadın bireylerin sayısı kemiklerin korunma durumunun zayıf olması sebebiyle oldukça az sayıda tahmin edilmiştir. Toplumda 7 kadın birey tahmin edilmiş olup içlerinden 3'ünün yaşları tahmin edilememiştir. 4 kadın bireyin verileri tablo yapılamadığı için yaş aralıkları şu şekilde dağılım göstermektedir. 3 kadın bireyin genç orta yetişkin, 1 kadın bireyin ise 45 yaş ve ileri yaşlarda olabileceği tahmin edilmiștir. Tablo 4'te Hasankeyf toplumunun erkek bireylerinin beşer yıl aralı yaş grubu yaşam tablosu gösterilmiştir.

\section{Tablo 4: Hasankeyf erkek bireylerinin beșer yıl aralı yaş grubu yaşam tablosu}

(X: Yaş aralıkları, Dx: $X$ yaşındaki ölümleri, $\mathrm{dx}=\mathrm{X}$ yaşındaki ölümlerin yüzdesini, Ix: $X$ yaşında hayatta kalanların sayısını, $q x=X$ yaşında ölüm olasılığı (ölümlülük olasılığı), Lx: yaşanan yılların sayısı, Tx: Yaşanan yılların toplamı, ${ }^{\circ}{ }_{*}$ : yaşam beklentisi).

\begin{tabular}{|l|l|l|l|l|l|l|l|}
\hline $\mathbf{X}$ & $\mathbf{D x}$ & $\mathbf{d x}$ & $\mathbf{I x}$ & $\mathbf{q x}$ & $\mathbf{L x}$ & $\mathbf{T x}$ & $\mathbf{e x}$ \\
\hline $\mathbf{2 0 - 2 4 , 9}$ & $\mathbf{0}$ & $\mathbf{0}$ & 100 & 0 & 416,675 & 1198,64 & 11,98 \\
\hline $\mathbf{2 5 - 2 9 , 9}$ & 4 & 33,33 & 66,67 & 0,49 & 291,7 & 781,97 & 11,72 \\
\hline $\mathbf{3 0 - 3 4 , 9}$ & 2 & 16,66 & 50,01 & 0,33 & 208,4 & 490,27 & 9,8 \\
\hline $\mathbf{3 5 - 3 9 , 9}$ & 2 & 16,66 & 33,35 & 0,49 & 164,25 & 281,87 & 8,45 \\
\hline $\mathbf{4 0 - 4 4 , 9}$ & 1 & 1 & 32,35 & 0,03 & 99,25 & 117,62 & 3,63 \\
\hline $\mathbf{4 5 - 4 9 , 9}$ & 3 & 25 & 7,35 & 3,4 & 18,37 & 18,37 & 2,49 \\
\hline
\end{tabular}

Tablo 4'e göre erkek bireylerin en fazla görüldüğü yaş grubu 25-29,99 yaş arasında 4 birey ile temsil edilmektedir. Ölüm oranı $(\mathrm{dx}$ ) yine bu yaş grubu arasında daha yüksek oranlarda görülmüştür. Erkek bireyler arasında hayatta kalma şansı (Ix), 20-24,99 ve 25-29,99 yaş arasında hızlı bir ivmeyle düşüş göstermiş, en az düşüş 40-44,9 yaş arasında görülmüştür. Illerleyen yaşla birlikte ölüm olasılığı (qx) eğimi yükselmiştir. Yaşam beklentisi oranı (ex), 20-34,99 yaş arasında hemen hemen aynı değerlerdeyken; 35-39,99 yaş arasında ani bir yükseliş gördükten sonra 40-44,99 yaş arasında ani düşüş eğilimi göstermiştir. 


\section{Tablo 5: Bebek ve çocuk bireylerin yaşam tablosu}

(X: Yaş aralıkları, Dx: $X$ yaşındaki ölümleri, $\mathrm{dx}=\mathrm{X}$ yaşındaki ölümlerin yüzdesini, $\mathrm{Ix}$ : $X$ yaşında hayatta kalanların sayısını, qX=X yaşında ölüm olasılığı (ölümlülük olasıllı̆ı), Lx: yaşanan yılların sayısı, Tx: Yaşanan yılların toplamı, ${ }^{\circ}{ }_{*}$ : yaşam beklentisi).

\begin{tabular}{|c|c|c|c|c|c|c|c|}
\hline$x$ & Dx & $d x$ & Ix & qx & Lx & $T x$ & ex \\
\hline $0-0,99$ & 5 & 18,51 & 100 & 0,18 & 453,725 & 3102,08 & 31,02 \\
\hline $1-1,99$ & 5 & 18,51 & 81,49 & 0,22 & 361 & 2648,35 & 32,49 \\
\hline $2-2,99$ & 0 & 0 & 62,98 & 0 & 314,9 & 2287,35 & 36,31 \\
\hline $3-3,99$ & 2 & 7,4 & 62,98 & 0,11 & 296,4 & 1972,45 & 31,31 \\
\hline $4-4,99$ & 2 & 7,4 & 55,58 & 0,13 & 240,875 & 1676,05 & 30,15 \\
\hline $5-5,99$ & 4 & 14,81 & 40,77 & 0,36 & 185,35 & 1435,18 & 35,2 \\
\hline $6-6,99$ & 2 & 7,4 & 33,37 & 0,22 & 157,6 & 1252,83 & 37,54 \\
\hline $7-7,99$ & 1 & 3,7 & 29,67 & 0,12 & 148,35 & 1095,23 & 36,91 \\
\hline $8-8,99$ & 0 & 0 & 29,67 & 0 & 139,1 & 946,88 & 31,91 \\
\hline $9-9,99$ & 1 & 3,7 & 25,97 & 0,14 & 129,85 & 807,78 & 31,1 \\
\hline $10-10,99$ & 0 & 0 & 25,97 & 0 & 129,85 & 677,93 & 26,1 \\
\hline $11-11,99$ & 0 & 0 & 25,97 & 0 & 129,85 & 548,08 & 9,32 \\
\hline
\end{tabular}




\begin{tabular}{|l|l|l|l|l|l|l|l|}
\hline $\mathbf{1 2 - 1 2 , 9 9}$ & 0 & 0 & 25,97 & 0 & 111,35 & 418,23 & 21,1 \\
\hline $\mathbf{1 3 - 1 3 , 9 9}$ & 2 & 7,4 & 18,57 & 0,39 & 92,85 & 306,88 & 16,52 \\
\hline $\mathbf{1 4 - 1 4 , 9 9}$ & 0 & 0 & 18,57 & 0 & 83,6 & 214,03 & 11,52 \\
\hline $\mathbf{1 5 - 1 5 , 9 9}$ & 1 & 3,7 & 14,87 & 0,24 & 65,1 & 130,43 & 8,77 \\
\hline $\mathbf{1 6 - 1 6 , 9 9}$ & 1 & 3,7 & 11,17 & 0,33 & 46,66 & 65,33 & 5,84 \\
\hline $\mathbf{1 7 - 1 7 , 9 9}$ & 1 & 3,7 & 7,47 & 0,49 & 18,675 & 18,675 & 2,5 \\
\hline
\end{tabular}

Tablo 5'e bakıldığında Hasankeyf bireylerinin \%37,02'sinin 0-2 yaş arasında öldüğü görülmektedir. Toplumdaki 0-0,99 yaş arasındaki bebeklerde yaşam beklentisi (ex), 31,02 yıldır. 1-10 yaş arasındaki bebek ve çocuk bireylerde yaşam beklentisi dalgalı bir seyir göstermekte iken yine de yükselen bir eğim vardır. 11-12 yaş arasında bir önceki yaşa göre ani bir düşüş görülmüş, sonraki yaşta artış gözlenmiştir. Daha sonraki yaşlarda yaşam beklentisi oranı düzenli olarak azalmıştır. Bu durum yaşam beklentisi grafiğine şu şekilde yansımaktadır (Grafik 5):

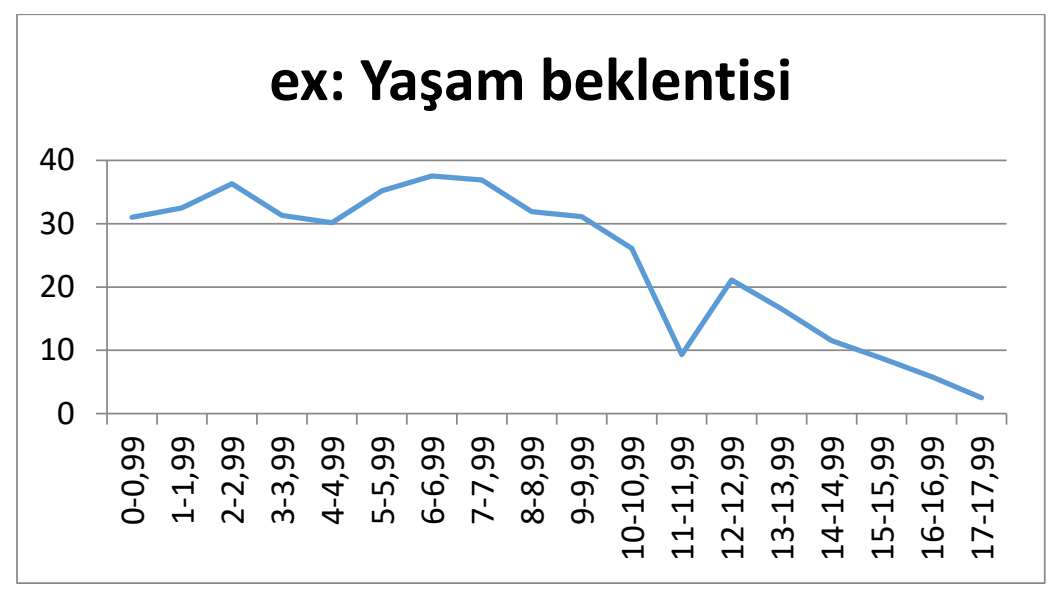

Grafik 5: Hasankeyf bebek ve çocuk bireylerin yaşam beklentisi 


\subsection{Boy Uzunluğu}

İnsanların fiziksel yapılarını ve sağlık durumlarını yansıtan göstergelerden biri olan boy uzunluğu için uzun kemikler (femur, tibia, humerus) tercih edilmiştir. Hasankeyf iskeletlerinin korunma durumunun zayıf olması, boy uzunluğu tahmini için kullanılan uzun kemiklere tam ve sağlam bir şekilde ulaşılmasına imkân tanımamaktadır. Sağlam olan kemik sayısının azlığına rağmen toplumun boy uzunluğu hakkında fikir sahibi olmak için yetişkin bireylerin uzun kemiklerinin metrik ölçümü Trotter ve Gleser'in geliştirdiği boy uzunluk formülü kullanılarak hesaplanmıştır. Bu hesaplamalara göre; femur kemiği 4 bireyde (3 erkek, 1 cinsiyeti tahmin edilemeyen) tam ve sağlam bir şekilde bulunmuştur. Hesaplamalar sonucunda 4 bireyin femur uzunluğuna göre boy uzunluğu ortalama 163,54 +- 3,94 cm'dir. Tibia kemiği 6 bireyde (1 kadın, 4 erkek, 1 cinsiyeti bilinmeyen) tam ve sağlam durumda tespit edilmiştir. Tibia uzunluğuna göre ortalama boy uzunluğu 171,38 +-4,00 cm olarak hesaplanmıştır. Humerus kemiği 4 erkek bireyde tam ve sağlam bir şekilde tespit edilmiştir. Humerus kemiğine göre ortalama boy uzunluğu 171,08+-4,57 cm olarak tahmin edilmiştir.

\subsection{Patolojik Bulgular}

Diş ve çene patolojilerinde çürük (Fotoğraf 2), apse (Fotoğraf 3), ölüm öncesi kaybı (Fotoğraf 4) ve diş taşı oluşumları incelenmiştir. İnceleme sonunda toplumda çürük görülme oranı \%2,56, apse \%2,38, antemortem diş kaybı \%29,25 ve diş taşı \%5,76'dır. Patolojiler cinsiyet açısından değerlendirildiğinde çürük erkek bireylerde, apse kadın bireylerde, antemortem diş kaybı ve diş taşı yine erkek bireylerde daha yüksek oranda tespit edilmiştir. Çürük orta yetişkin grupta, antemortem diş kaybı ileri yaş grubunda daha yüksek oranda görülmüştür.

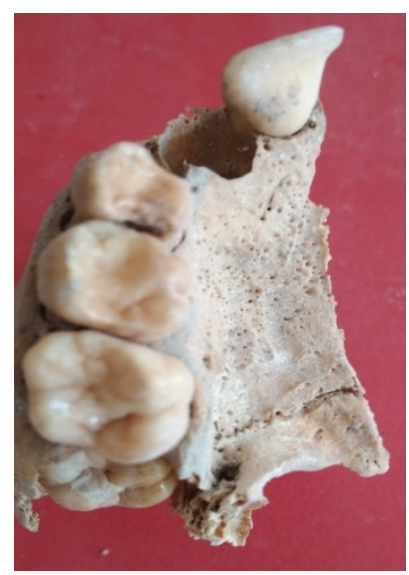

Fotoğraf 2: M59 no.lu birey maxilla süt M1'de çürük 


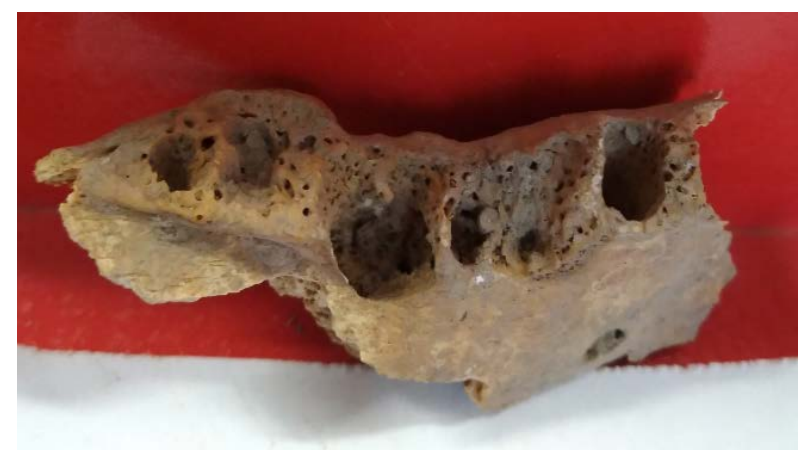

Fotoğraf 3: M5 no.lu birey mandibula M1'de apse

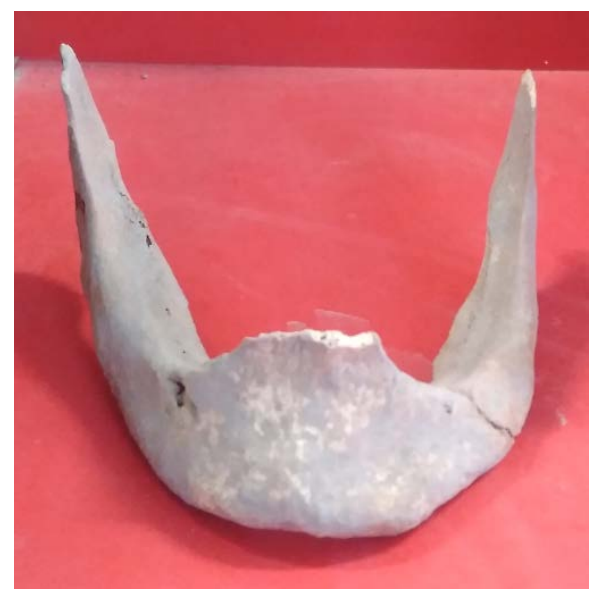

\section{Fotoğraf 4: M25A no.lu birey mandibula ölüm öncesi diș kaybı}

Kemiklerin korunma durumunun zayıf olması nedeniyle vücut patolojilerine ait az sayıda patoloji tespit edilmiştir. Hasankeyf bireylerine ait vücut patolojileri incelendiğinde $\mathrm{M}_{5}$ no.lu mezarda yetişkin bireye ait olan humerus kemiğinde travma tespit edilmiştir (Fotoğraf 5). Bu mezarda 2 birey bulunmakta ve iki birey de yetişkin olarak tahmin edilmiştir. M42 no.lu mezardaki kemiklerin korunma durumu oldukça zayıf olup bu mezarda 1 kişi tahmin edilmiştir. Kafatasına ve birçok vücut kemiğine ait kalıntı tespit edilememiştir. Bireyin cinsiyeti ve yaşı tahmin edilememiştir. Içinde 3 adet küçükbaş hayvana ait kalıntı tespit edilmiştir. M42 no.lu yetişkin bireyin tibia kemiğinin distal ucunda kemik çıkıntılar tespit edilmiştir (Fotoğraf 6). 


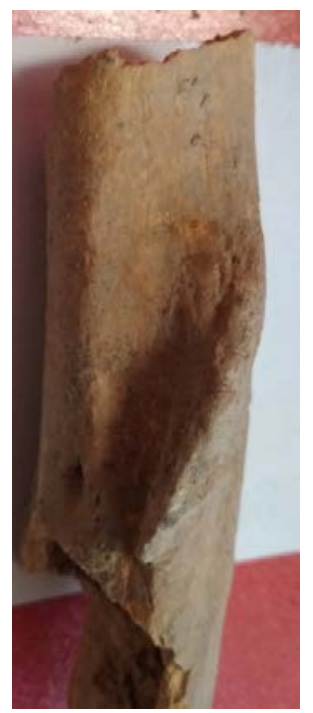

Fotoğraf 5: M5 no.lu birey humerus'te travma

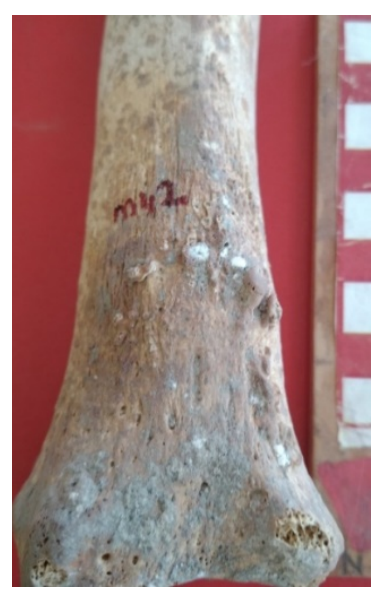

Fotoğraf 6: M42 no.lu birey tibia'da kemik çıkıntı

\section{Tartışma}

Arkeolojik kazılar sonucunda çıkarılan insan iskelet kalıntılarından yapılan demografik analizler, toplumların yaşam biçimlerine ait bilgiler sunar. Toplumdaki bireylerin ölüm yaşlarına ilişkin bilgiler ile toplumun genel sağlığı hakkında fikir sahibi olarak çağdaş ve yakın dönemde yaşamış toplumlar arasında bir karşılaştırma yapılabilir. 
Hasankeyf bireylerinin bebek ve çocuk ölüm oranlarına bakıldığında, bu oranın toplumun \%34,14'ünü (N:28) oluşturduğu hesaplanmıştır. En yoğun ölümlerin 1-5 yaş arasındaki bireylerde \%13,41 oranında görülmüştür. Yaşamın ilk 5 yılında gerçekleşen yoğun ölümler toplumdaki bireylerin yetişkinlik aşamasına ulaşamadan hayatta kalma şansını \% 69,56'a düşürmektedir. Bebek ve çocuk bireylerin ortalama yaşam uzunlukları 5,78 yıl olarak tahmin edilmiştir. Yaşamın erken dönemlerinde alınan anne sütünün, bebeklerin olumsuz koşullara karşı bağışıklığında yüksek oranda koruyuculuk taşımaktadır. Anne sütü yanında ek gıdaya başlama dönemi içinde bulunan 1-5 yaş arasındaki bireylerin bu dönemde olumsuz çevre şartlarına karşı daha zayıf özellikler taşımasından dolayı ölümlerin bu yaş aralığında yüksek oranda olması beklenir. Hasankeyf toplumunda da aynı durum gözlenmiştir. Hasankeyf ile çağdaş ve yakın dönem Eski Anadolu toplumları üzerinde yapılan çalışmalarda (Gözlük, 2005; Sevim vd., 2006; Yiğit vd., 2008; Erdal ve Özbek, 2009; Yiğit vd., 2010; Özer vd., 2016; Akbaş ve Özer, 2020) bebek ve çocuk ölümlerinin önemli oranının yaşamın ilk yıllarında olduğu ifade edilmektedir.

Çalışmada, yapılan değerlendirmeler ile toplum genelindeki yetişkin bireylerin ortalama yaşam ömürleri 35,55 yıl olarak hesaplanmıştır. Ortalama yaşam uzunlukları açısından çağdaşı eski Anadolu toplumları ile karşılaştırılması Tablo 6'da gösterilmiștir. Tabloya göre Hasankeyf toplumunun ortalama yașam uzunlukları, Havuzdere (Özer vd., 2016) ve Müslümantepe (Akbaş ve Özer, 2020) toplumlarına yakınlık göstermektedir. Hasankeyf toplumunun yaşam uzunlukları ortalaması Karagündüz (Gözlük, 2005) ve Güllüdere (Sevim vd., 2006) popülasyonlarının altında kalmıştır. Fakat bu popülasyonlarda yüksek orandaki bebek ve çocuk ölümleri de dikkati çekmektedir. Toplumların sağlık durumları ve sosyo-ekonomik düzeyleri, yaşam uzunluklarını etkileyen etmenler arasındadır. Toplumların farklı yaşam alanlarının ve koşulları bu durumla yakından etkilidir.

Tablo 6: Anadolu'da yaşamış toplumlarda erişkin ortalama yaşam uzunlukları ve bebek, çocuk ölüm oranları

\begin{tabular}{|c|c|c|c|c|c|}
\hline Popülasyon & Dönem & Araştırmacı & $\begin{array}{l}\text { Birey } \\
\text { Sayısı }\end{array}$ & $\begin{array}{l}\text { Yaşam } \\
\text { Uzunlukları } \\
\text { Ortalaması }\end{array}$ & $\begin{array}{l}\text { Bebek ve } \\
\text { Çocuk Ölüm } \\
\text { Oranları \% }\end{array}$ \\
\hline Karagündüz & $\begin{array}{l}\text { Orta } \\
\text { Çağ }\end{array}$ & Gözlük, 2005 & 890 & 37,08 & 58,2 \\
\hline
\end{tabular}




\begin{tabular}{|c|c|c|c|c|c|}
\hline Güllüdere & $\begin{array}{l}\text { Orta } \\
\text { Çağ }\end{array}$ & Sevim vd., 2006 & 36 & 39,44 & 50 \\
\hline Minnetpınarı & $\begin{array}{l}\text { Orta } \\
\text { Çağ }\end{array}$ & Yiğit vd., 2008 & 86 & 31,87 & 17,44 \\
\hline Van Kalesi & $\begin{array}{l}\text { Orta } \\
\text { Çağ }\end{array}$ & $\begin{array}{l}\text { Erkman ve Alkan, } \\
2011\end{array}$ & 315 & 41,71 & 51,11 \\
\hline Havuzdere & $\begin{array}{l}\text { Orta } \\
\text { Çağ }\end{array}$ & Özer vd., 2016 & 352 & 35,27 & 34,38 \\
\hline Müslümantepe & $\begin{array}{l}\text { Orta } \\
\text { Çağ }\end{array}$ & $\begin{array}{l}\text { Akbaş ve Özer, } \\
2020\end{array}$ & 459 & 33,46 & 39,87 \\
\hline Hasankeyf & $\begin{array}{l}\text { Orta } \\
\text { Çağ }\end{array}$ & Bu çalıșma & 82 & 35,55 & 34,14 \\
\hline
\end{tabular}

Boy uzunluğu tahmini; beslenme, genel sağlık yapısı ve sosyo-ekonomik durumu değerlendirmek için fikir verebilir. Hasankeyf bireylerinin kalıntılarının korunma durumunun zayıf olması nedeniyle tam ve sağlam durumdaki uzun kemik sayısı oldukça azdır. Boy uzunluğu tahmini için verilerin azlığı diğer çağdaşı Anadolu toplumları ile karşılaştırmaya olanak tanımamaktadır.

Hasankeyf bireylerine ait diş patolojileri yakın dönem Anadolu'da yaşamış bireylerle karşılaştırılmıştır. Bu toplumlar Midyat-Aktaş (Acar, 2018), VanKaragündüz (Gözlük Kırmızıoğlu, 2018), Zeytinli Ada (Bıçak ve Suata Alpaslan, 2015), Minnetpınarı (Yaşar, 2007), Kelenderis (Çırak vd., 2013), Dara (Acar, 2017), Akgüney (Şarbak, 2019), Tokat-Niksar (Torun ve Gözlük Kırmızıoğlu, 2015)'dır. Hasankeyf toplumu incelenen tüm popülasyonlar arasında en düşük oranda (\% 2,56) diş çürüğüne sahiptir. Toplumların beslenme biçimlerinin diş ve çene patolojilerine etkileri düşünüldüğünde Hasankeyf toplumunda çürük oranın düşük olmasının, bu toplumun beslenme diyetinde hayvansal ürünler olabileceği ile ilgili tahmin edilmektedir. Çürük oluşumunun diğer nedenleri arasında erken 
yaşta apse ve diş kayıplarının yaşanması sayılabilir. Tarıma dayalı toplumlarda çürük oranı daha yüksek oranlarda görülmektedir. Apsenin oluşum nedenleri arasında aşınma ve çürüme sayılabilir. Çürük oranın düşük olması apse oranında da bu doğrultuda benzerlik göstermesi tahmin edilebilir. Apse oranına bakıldığında Hasankeyf toplumu; Kelenderis, Akgüney, Dara, Van-Karagündüz toplumları ile yakın benzerlik göstermekte iken Midyat-Aktaş, Zeytinli Ada, TokatNiksar toplumlarında apse, yüksek orandadır. Hasankeyf toplumunun karşılaştırılan Anadolu toplumlarıyla arasında belirgin bir farklılık taşımadığı, çağdaşı ve döneminde yaşayan insanlara benzer bir hayat sürdükleri tahmin edilmiştir.

Vücut patolojileri, iskeletlerin korunma durumunu zayıf olması nedeniyle yeterli düzeyde incelenememiştir. Yine de toplumun sağlık yapısının iyi olduğu söylenebilir. Toplumda 45 yaş üstü bireylerin fazla sayıda olmaması, toplumda erken yaşta ölümlerin görülmesi ve özellikle 0-5 yaş arasındaki bireylerde yüksek ölümlülük oranı olması gibi durumlar bir arada değerlendirildiğinde Hasankeyf toplumundaki bireylerin genel sağlık yapılarının iyi olduğu fakat toplumun dönemsel koşullardan fazla etkilenmiş olabileceği tahmin edilmiştir.

\section{Sonuç}

Yapılan arkeolojik kazılar ile ortaya çıkarılan insan iskelet kalıntılarının paleodemografik analizleri, Anadolu'da yaşamış geçmiş toplumları daha iyi tanımak için katkı sunmaktadır.

Çalışmadaki materyaller, Hasankeyf ilçesi, Ilısu kurtarma kazısı kapsamında 2019 yılı içinde Er Rızk Camii alanında bulunan P237 no.lu parselde güneyden kuzeye A1 ve B1 plan karelerinden çıkarılan basit toprak mezar özelliği taşıyan 63 adet mezardaki 82 bireyin iskeletlerini içermektedir. Toplumdaki bireylerin \% 23,17'i erkek, \%8,5'i kadın, \%34'ü bebek ve çocuk olarak tahmin edilirken, \%34'ünde cinsiyet tahmin edilememiştir.

Toplumdaki ölüm oranı en fazla genç orta yetişkin ve 0-5 yaş arasındaki bebek ve çocuklarda görülmüştür. Bebeklerde bu oranın yüksek olması, beslenme ve sağlık koşullarının yeterli olmaması sonucu olabileceği tahmin edilmiştir. Yetişkin grubundaki oranın yüksek olması ve ileri yaş bireylerin sayısının az olmasının nedeni olarak, yaşam koşullarının ve çevresel faktörlerin bireyleri olumsuz etkilediği düşünülmektedir. Kadınların sayıca az olması ve erken yaşlarda ölmesinin nedeni ise doğum sonrası dönemin yeterli sağlık koşullarını sağlamaması olarak tahmin edilmiştir.

Boy uzunluğu için yeterli sayıda tam ve sağlam uzun kemik olmamasına rağmen en fazla sayıda bulunan tibia kemiğine Trotter ve Gleser'in geliștirdiği formül uygulandığında, ortalama boy uzunluğu 171,38 +-4,00 cm olarak bulunan 
Hasankeyf toplumunun çağdaşı Anadolu toplumlarından daha uzun oldukları söylenebilir.

Diş patolojilerinin değerlendirilmesi sonucu Hasankeyf toplumunun bölgenin şartlarına uygun bir beslenme diyeti ile beslendiği ve diyetinin hayvansal gıdaya yönelik olduğu söylenebilir. Vücut patolojilerinde ağır patolojik vakalar tespit edilmemiştir. Toplumun genel sağlık durumun iyi olduğu tahmin edilmiştir.

Sonuç olarak, Orta çağa tarihlendirilen Hasankeyf toplumu, Güneydoğu Anadolu bölgesi için önemli bir yere sahiptir. Dönemindeki demografik yapıyı daha iyi anlayabilmek için karşılaştırmalı veri kaynağı niteliği sunmaktadır. Bu çalışmanın Hasankeyf üzerinde yapılan bilimsel çalışmalara, bölgedeki insanların genel sağlık durumu ve toplumsal yapının belirlenmesi ile katkı sunması amaçlanmıştır.

\section{Teșekkür}

Hasankeyf Ören Yeri'ndeki 2019 yılı Arkeolojik Kazı çalışmaları Batman Müze Müdürlüğü başkanlığında Dr. Öğr. Üyesi Mevlüt Eliüşük'ün bilimsel danışmanlığında gerçekleştirilmiştir. Bu iskeletleri çalışmam için gerekli izinleri veren Batman Müze Müdürü Şehmus Genç'e, iskeletlerin çıkarılma ve ulaştırılması aşamasında yardımlarını esirgemeyen Dr. Öğr. Üyesi Mevlüt Eliüşük'e teşekkürü bir borç bilirim. Kazı heyet üyesi Dr. Öğr. Üyesi Zekai Erdal hocama da desteklerinden dolayı teşekkür ederim.

\section{Kaynakça}

Acar, A. (2017). Dara Antik Kent Kazısı Antropolojik Analiz. Arkeometri Sonuçları Toplantısı, 33:101-116.

(2018). Mardin Midyat Aktaş Mevkii Insan İskeletlerinde Diş ve Çene Patolojileri. Mukaddime, 9(1), 151-172 DOI: 10.19059/mukaddime.353493,151172.

Akbaş, N., ve Özer, i.. (2020). Müslüman Bir Orta Çağ Topluluğu Olan Müslümantepe (Diyarbakır) Yerleşiminde Yaşam Uzunluğu. Antropoloji, (39), 1-17. https://doi.org/10.33613/antropolojidergisi.709905

Angel, J. L. (1969). The Basis of Paleodemography. American Journal of Physical Anthropology, 30: 427-438.

Aufderheide, C. \& Conrado Rodríguez-Martín, (1998). The Cambridge Encyclopedia of Human Paleopathology. Cambridge University Press.

Bass, W. M. (1995). Human Osteology: A Laboratory and Field Manual. 4th. edition. Special Publication No. 2. Missouri: Missouri Archaeological Society.

Bıçak, S. ve Suata Alpaslan, F. (2015). Zeytinli Ada İskelet Topluluğunun Diş ve Çene Patolojisi Açısından İncelenmesi. Cumhuriyet Üniversitesi Fen Fakültesi Fen Bilimleri Dergisi (CFD), Cilt:36, S.32-46. 
Brothwell, D. R. (1981). Digging up Bones: The Excavation, Treatment, and Study of Human Skeletal Remains. Cornell University Press.

Buikstra, J. E. \& Ubelaker, H. D. (1994). Standards for Data Collection From Human Skeletal Remains. Fayetteville: Arkansas Archeological Survey Research Series No. 44.

Çırak, A., Çırak, M. T., ve Erkman, C. A. (2013). Kelenderis Halkının Diş ve Çene Patolojileri, OLBA, 21, 1-25.

Çöloğlu, A. S. \& İşcan, M. Y. (1998). Adli Osteoloji. İstanbul Üniversitesi Rektörlük Yayınları, İstanbul.

Demirjian, A., Goldstein, H. ve Tanner, J. M. (1973). A New System of Dental Age Assessment. Human Biology, 45:211-227.

Erdal, Ö. D. ve Özbek, M. (2009). Değirmentepe (Malatya) Çocuk İskeletlerinin Antropolojik Analizi, 25. Arkeometri Sonuçları Toplantısı, 279-296.

Erdal, Y. S. (2011). Tasmasor Geç Demir Çağı İskeletlerinin Antropolojik Analizi. In: Tasmasor. Şenyurt SY (ed.), Bilgin Yayınları, Ankara.

Erkman, A. C., ve Alkan, Y. (2013). 2010-2011 Van Kalesi Höyüğü İskeletlerinin Paleodemografik Analizi. Arkeometri Sonuçları Toplantısı, 28, 97-102.

Gözlük Kırmızıoğlu, P. (2018). Van-Karagündüz (Ortaçağ) Erişkin Bireylerinin Dental Patoloji Analizi, Cumhuriyet Dental Journal, 21(1): 1-8.

Gözlük, P. (2005). Karagündüz Toplumunun Paleodemografik Açıdan İncelenmesi, Ankara Dil Tarih Coğrafya Fakültesi Antropoloji Dergisi, Sayı 20:75-106.

Güleç, E., Akın, G., Sağır, M., Koca Özer, B., Gültekin, T., ve Bektaş, Y. (2009). Anadolu Insanının Antropometrik Boyutları: 2005 yılı Türkiye Antropometri Anketi Genel Sonuçları. Ankara Üniversitesi Dil ve Tarih-Coğrafya Fakültesi Dergisi, 49(2), 187-201.

Hillson, S. (1990). Teeth, New York: Cambridge University Press.

İscan, M. Y. ve Miller-Shaivitz, P. (1984). Determination of Sex From the Tibia. American Journal of Physical Anthropology, 64:53-58.

Krogman, W. M. \& İşcan, M. Y. (1986). The Human Skeleton in Forensic Medicine. Springfield, IL: Charles C. Thomas.

Lovejoy, C. (1985). Dental Wear in Libben Population: Its Functional Pattern and Role in the Determination of Adult Skeletal Age at Death. American Journal of Physical Anthropology 68:47-56.

Meindl, R. S., ve Russell, K. F. (1998). Recent advances in method and theory in paleodemography. Annual Review of Anthropology, 27(1), 375-399.

Olivier, G. (1969). Practical Anthropology. Charles C. Thomas Publisher, Springfield, Ilionis.

Ortner, D. J. \& Putschar, W. (1981). Identification of Pathological Conditions in Human Skeletal Remains. Washington: Smithsonian Institution Press.

Özer, I.., Sağır, M., Koca Özer, B., Karatufan, A., ve Şahin, S. (2016). Havuzdere Orta Çağ İskeletlerinin Paleoantropolojik Analizi. Ankara Üniversitesi Sosyal Bilimler Dergisi, 7(2), 47-57. 
Perizonius, W. (1984). Closing and Non-closing Sutures in 256 Crania of Known Age and Sex from Amsterdam (A.D.1883-1909). Journal of Human Evol. 13:201-216.

Scheuer, L. \& Black, S. (2000). Developmental Juvenile Osteology. New York: Academic Press.

Sevim, A., Gözlük Kırmızıoğlu, P., Yiğit, A., Özdemir, S. ve Durgunlu, Ö. (2006). Erzurum/Güllüdere İskeletlerinin Paleoantropolojik Açıdan Değerlendirilmesi, 22. Arkeometri Sonuçları Toplantısı, 141-160.

Şarbak, A. (2019). Akgüney İskelet Toplumu Dişlerin Paleopatolojik Açıdan Incelenmesi, Antropoloji, 38: 5-19.

Torun, N. ve Gözlük Kırmızıoğlu, P. (2015). Tokat (Niksar) İskeletlerinde Diş ve Çene Patolojileri. Cumhuriyet Üniversitesi Sosyal Bilimler Dergisi, 39 (2): 4770.

Trotter, M. ve Gleser, G. C. (1951). Estimation of Stature From the Long Bones of American Whites and Blacks. American Journal of Physical Anthropology, 10:463-514.

Ubelaker, D. H. (1991). Human Skeletal Remains: Excavation, Analysis, Interpretation (Second edition). Taraxacum.

Üner, S. (1972). Nüfusbilim Sözlüğü, Hacettepe Üniversitesi Yayınları D17, Ankara. Workshop of European Anthropologists. (1980). Recommendations for Age and Sex Diagnosis of Skeletons. Journal of Human Evolution, 9: 517-549.

Yaşar, Z. F. (2007). Adli Dental Antropoloji: Dental Antropoloji Açısından Minnetpınarı ve Güllüdere Toplumlarının Dişlerinin Karşılaştırmalı Analizi, (Basılmamış Doktora Tezi), Ankara: Ankara Üniversitesi Sosyal Bilimler Enstitüsü.

Yiğit, A., Gözlük Kırmızıoğlu, P., Durgunlu, Ö., Özdemir, S., ve Sevim Erol, A. (2008). Kahramanmaraş/Minnetpınarı İskeletlerinin Paleantropolojik Açıdan Değerlendirilmesi. Arkeometri Sonuçları Toplantısı, 23, 91-110.

Yiğit, A., Yılmazer Salihoğlu, N., Gözlük Kırmızıoğlu, P., Yaşar, Z. F., Kesikçiler, B., ve Sevim Erol, A. (2010). Trabzon Kızlar Manastırı Insan İskeletlerinin Antropolojik Açıdan Değerlendirilmesi. Arkeometri Sonuçları Toplantısı, 25, 105-126. 